\title{
Damage Control Resuscitation and Surgery in a Forward Combat Setting
}

\author{
Jamison S. Nielsen ${ }^{1}$ • Justin Watson ${ }^{2}$
}

Published online: 6 June 2016

(C) Springer International Publishing AG (outside the USA) 2016

\begin{abstract}
Purpose of Review Surgical management of the severely injured trauma patient is a balance between managing abnormal physiology and performing definitive repair of injuries. When hemodynamic impairment is present immediate care consistent with Advance Trauma Life Support (ATLSTM) guidelines is required. However, associated vascular and/or visceral compromise carry significant morbidity and mortality that must be addressed.

Recent Findings This equilibrium, now manifest in the principles of damage control resuscitation, is the standard approach in trauma surgery. In the setting of combat, a remote and resource-limited environment, several other concerns affect management decisions.

Summary Combat casualty care must take into consideration pre-hospital interventions, location, triage, supply, personnel, transportation, security, and operational conditions specific to theaters of conflict. Ultimately damage control is one of many forms of triage within the greater scope of trauma care.
\end{abstract}

Keywords Damage control surgery · Military ·

Resuscitation $\cdot$ Austere $\cdot$ Injuries $\cdot$ Trauma

This article is part of the Topical Collection on The Military Perspective

Jamison S. Nielsen

nielsenj@ohsu.edu; jamison.nielsen@gmail.com

1 Division of Trauma, Critical Care \& Acute Care Surgery, Oregon Health \& Science University, 3181 SW Sam Jackson Park Road, Mail Code: L611, Portland, OR 97239, USA

2 General Surgery, Oregon Health \& Science University, 3181 SW Sam Jackson Park Road, Mail Code: L611, Portland, OR 97239, USA

\section{Introduction}

High casualty volumes and remote, austere locations have accelerated care advancements for the combat wounded during recent military engagements. Improvements in care have been dramatic, resulting in over a $95 \%$ survival rate once a patient reaches the medical treatment facility (MTF) $[1 \bullet]$. As such, most deaths are now occurring in the pre-hospital setting [2]. Attention is being shifted to address this population of potentially salvageable casualties through the development of a remote damage control resuscitation (RDCR) initiative [3••]. Since the initial introduction of damage control surgery (DCS) in 1983, its application has broadened to include resuscitation and ICU management [4, 5]. Damage control resuscitation (DCR) has evolved from surgical techniques to a full "continuum of care" including all stages of patient management [6]. Intuitively, the full spectrum of care should include system practices and operational planning. There is a long history of military and civilian trauma care providers informing each other's practice and the current era is no exception. However, the focus of this discussion will center on the forward military setting and its unique challenges.

\section{Readiness}

Before addressing the practical concerns of specific, individual resuscitative interventions it is important to consider preparation from a systems perspective. In military parlance, this is encapsulated by the term "operational readiness" which is defined as:

"The capability of a unit/formation, ship, weapon system, or equipment to perform the missions or functions for which it was organized or designed [7]." 
Preparation and readiness are intrinsically related. The importance of preparation is elevated in austere conditions when absent or non-mission capable equipment, supplies, or personnel cannot readily be replaced. Preparation also addresses system-based practice which must be considered before the first casualty arrives. In the chaotic environment of combat, the roles of each team member must be reflexive in nature. Considerations surrounding interventions and evacuation should be pre-determined for the most effective response. We know from civilian medical care that errors are more frequently caused by "faulty systems, processes, and conditions" than failure on the individual level [8]. A well-equipped and trained team within a robust logistical framework from the point of injury (POI) to definitive care is the best opportunity for improving injury outcomes.

The starting point for the US military is the modified table of organization and equipment (MTOE) representing a list of authorized personnel and equipment [7]. However, every mission will vary and modifications may be required from the initially anticipated resources. An iterative process known as the medical decision making process (MDMP) is a supported tool to optimize having the right people and equipment at the right place and time [9]. Professional and team development also is integral to the success of the preparation phase and can present a challenge during inter-war periods. Lessons from prior wars have often had to be re-learned during recent operations and preserving the lessons and experience already obtained is critical.

\section{Pre-hospital Care, Scene Security, and Evacuation}

The pre-hospital setting in combat environments is the epitome of austere medical care (Fig. 1). Ongoing fire fights may be occurring, supplies are typically restricted to what can be carried, polytrauma due to blast forces are frequent, rapid hemorrhage is a common presentation, extremes of temperature can be found, and the geographical location/terrain may have limited access. A recent analysis of potentially preventable combat deaths found that the majority $(87 \%)$ occur in the pre-hospital setting and are due to exsanguinating hemorrhage
[2]. Significant advances have been made in the surgical care of military trauma patients and now the "next great leap forward" in survival is anticipated in the pre-surgical setting through the RDCR model [10]. As we understand more regarding the acute coagulopathy of trauma (ACT) early intervention, pushed forward to the POI has become essential $[10-13,14 \bullet]$.

The Tactical Combat Casualty Care (TCCC) Guidelines divides POI care into three phases - care under fire, tactical field care, and tactical evacuation care. The first priority upon encountering a casualty (care under fire phase) is scene safety to include returning fire if necessary, obtaining cover, and prevention of additional injuries. In this first phase, early interventions to decrease the effects of flame (evacuation/extinguish) and self-aid/buddy-aid to apply tourniquets are employed. Airway, which is typically the first priority in ATLS, is deferred to the second, field care, phase of TCCC. Once the patient and provider have appropriate cover/distance, the tactical field care phase begins. This follows the familiar primary survey progression with the exception that patients with altered mental status should first be disarmed $[15,16]$.

The maneuvers employed in tactical field care are described in Table 1. Particular attention is focused on hemostatic and circulatory resuscitative maneuvers. External hemorrhage is treated with compression and zeolite-impregnated dressings (Combat Gauze, Wallingford, CT) for initial control. If topical approaches are inadequate to address hemorrhage such as injury location, type, transport concerns, or continued hemorrhage, a tourniquet is applied. The Combat Application Tourniquet (CAT, North American Rescue, Greer, SC) can be placed by the casualty or responder either directly on the extremity or over clothing and is currently carried by all warfighters. Tranexamic acid (TXA) is administered if large volume hemorrhage is expected. The fluid replacement of choice best matches that which was lost-whole blood. The full list of resuscitation fluids for casualties with evidence of hemorrhage-induced shock are listed by priority in Table 2 .

Non-compressible torso hemorrhage $(\mathrm{NCTH})$ remains a continuing resuscitative dilemma in the pre-hospital setting. One device for NCTH control developed recently is the

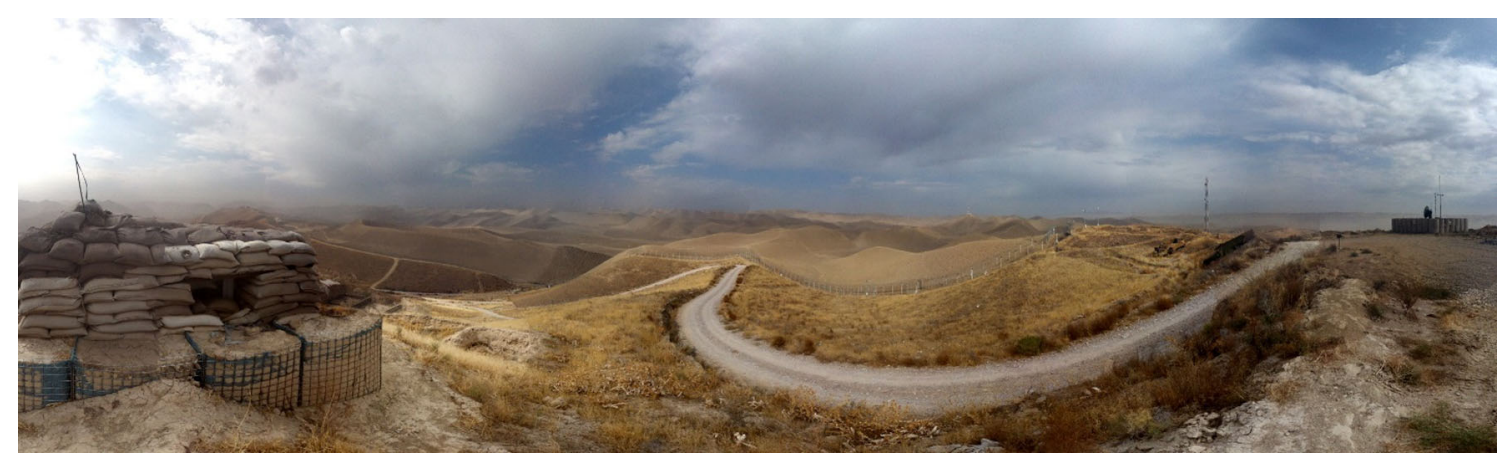

Fig. 1 Typical example of an austere military setting 
Table 1 Tactical combat casualty care maneuvers

1. Airway adjuncts (example: nasopharyngeal, King airway)

2. Endotracheal intubation

3. Crichothyroidotomy

4. Needle and tube thoracostomy

5. Tourniquet placement (extremity or junctional)

6. Intravenous or intraosseous access

7. Fluid resuscitation

8. Hypothermia prevention

9. Eye trauma stabilization

10. Monitoring for instability, shock, and hypothermia

11. Analgesia

12. Splinting of fractures

13. Burn stabilization

14. Disarming of patient

[10]

[16]

Abdominal Aortic and Junctional Tourniquet (AAJT, Compression Works, Birmingham, AL). It represents one of several commercially available devices now with reports of use in combat for aortic, axillary, and inguinal hemorrhage. The AAJT is comprised of a wide belt which is secured, tightened with a windlass (similar to an extremity tourniquet), and followed by inflation of an air bladder to reach complete vascular occlusion $[17,18,19 \bullet, 20]$. Another alternative to NCTH control still under investigation is intraabdominal selfexpanding foam. After instillation in the abdominal cavity, a tamponade effect temporizes hemorrhage until arrival at the MTF when laparotomy for foam removal a vascular repair is required. A polyurethane polymer designed for administration by the first responder has demonstrated a survival advantage in animal models [21, 22•, 23].

Vital sign targets of resuscitation have been the focus of discussion in recent years, specifically if fluids are provided to achieve normal blood pressure in the pre-hospital setting. There has been concern that crystalloid infusions can create dilution and modification of the coagulation profile resulting in clot instability and continued hemorrhage. The alternative,

Table 2 Pre-hospital resuscitation fluid of choice for hemorrhagic shock

1. Whole blood

2. Plasma, RBCs and platelets in 1:1:1 ratio

3. Plasma and RBCs in 1:1 ratio

4. Plasma and RBCs alone

5. Hextend

6. Crystalloid (lactated ringers or plasma-lyte A)

[15]

Contingent on availability and local regulations hemostatic resuscitation, which was framed in a trial comparing early versus delayed fluid administration in the 1990s has gradually gained acceptance [24]. Hemostatic resuscitation is advocated in the current TCCC guidelines with goals of either a palpable radial pulse, improved mental status, or SBP of 80$90 \mathrm{mmHg}$. If a known or suspected traumatic brain injury (TBI) is present, the target SBP is at least $90 \mathrm{mmHg}$ [16].

The pre-hospital environment is notoriously unpredictable in terms of climate control. Controlling the patient's temperature from extremes is one mechanism to limit the "lethal triad" of which hypothermia is a part. This can be accomplished through using the casualty's own gear, exchanging wet clothing, warm fluids, and use of either commercially available or improvised warming/insulating systems [15]. Hypothermia prevention is challenging during evacuation particularly when transport times are great and/or airframes with open transport bays are employed.

As the patient is moved away from the POI to the MTF, evacuation care commences, which is the third stage of TCCC. Tactical evacuation care mirrors the priorities and recommendations of field care with the caveat of some considerations specific to the type of transport. For dedicated evacuation platforms, the type of equipment and supplies are generally more protocolized and robust than immediate field care as they are not directly carried on the person. Two platforms, MEDEVAC and CASEVAC, are used for casualty evacuation with the former being dedicated to en route medical care whereas the latter is a conveyance of convenience. The primary survey and maneuvers are modified only in regard to changes in personnel capabilities (i.e., paramedic vs field medic) and transport concerns such as altitude, noise, space, and movement. Notification and planning for evacuation is initiated with a nine-line medical evacuation request. The nine-line format is a standardized format to crucial information in as concise a message a possible. The components of the nine-line (in order) are (1) pickup location, (2) communication frequency/parameters, (3) number of patients by precedence type, (4) required equipment (i.e., hoist, vent), (5) number of patients by litter/ambulatory status, (6) site security category, (7) method of marking to be used at the pickup, (8) patient nationality/status, and (9) terrain specifics/concerns [25].

\section{Initial Treatment Facility Triage}

Once the casualty arrives at the MTF (such as a forward surgical team-FST), resources remain limited, but treatment possibilities are expanded. Ongoing triage occurs for casualties arriving at the MTF level, both at the scale of the individual and census of patients at the MTF. Triage is a mechanism to properly utilize resources which are overwhelmed by the quantity and injury severity of patients. The goal is to provide the most benefit within the constraints present. DCR is simply 
a form of triage in which the limited resource at the patient level is time. The approach of rapid hemostatic and contamination control maneuvers with delay of non-essential definitive procedures is protective against coagulopathy and exsanguination. At the MTF level, a mass casualty situation will, by definition, overwhelm local capabilities. The US military employs a triage system that takes resources into account and provides a mechanism for re-assignment of category if the resource situation changes. The four categories used are:

- Immediate: These patients require attention within minutes -2 hours to avoid mortality or loss of vital function without intervention. Increased priority is given to those with a higher likelihood of survival.

- Delayed: These patients require an intervention, but delay does not present an immediate threat to life or function.

- Minimal: These patients require little medical attention and can often provide self-care. However, these patients can divert limited resources which can impair the outcomes of the more severely injured.

- Expectant: These patients require large amounts of resources with minimal chance of recovery. Focus is centered on compassionate palliation unless the MTF resources and capabilities change.

In isolated locations, not only do current casualties direct triage decisions, but anticipated casualties must be taken into account for resource utilization [26]. After triage, and sometimes concurrently, the casualties will undergo standard primary and secondary surveys as part of a complete trauma evaluation.

\section{Damage Control Resuscitation}

Hemorrhage remains the leading cause of preventable death after trauma in the first 48 hours [27, 28]. Historically, resuscitation strategies have varied with foci on preoperative, intraoperative, and postoperative care. DCR is an evolving field focused on coagulopathy correction and hemorrhage control from POI to postoperative management. Research into optimal RDCR strategies to minimize mortality and morbidity include the following: early lyophilized plasma (LP) utilization, novel plasma reconstitution methods, balanced product resuscitation, fresh whole blood (FWB) transfusion, controlled resuscitation, and tranexamic acid (TXA) administration.

DCR aims to mitigate exacerbation of hemorrhage caused by ACT and iatrogenic coagulopathy (IC). The acute coagulopathy of trauma is present in at least $25 \%$ of severely injured individuals and up to $60 \%$ of patients with severe traumatic brain injury (TBI) [29]. Principal drivers of ACT that have been observed in the field prior to resuscitation include the following: tissue hypoperfusion, hyperfibrinolysis, inflammation, acute activation of the neurohumoral system, and the endotheliopathy of trauma (EOT) [30-33, 34•, 35-38]. ACT has been shown to be an independent predictor of mortality [39, 40]. These clinical findings are separate from iatrogenic coagulopathy (IC) which is attributed to crystalloid-induced acidosis, hypothermia, and dilution [33, 34•, 35, 36, 38].

Plasma has been demonstrated to reverse ACT, IC, and EOT improving survival even without red cell transfusions $[41 \cdot, 42-45]$. POI plasma offers several significant physiological and logistical advantages over crystalloid resuscitation fluids or fresh frozen plasma (FFP) [44, 46••, 47]. Physiological improvements include reduced iatrogenic coagulopathy, improved endothelial function, a more physiological $\mathrm{pH}$, and improved maintenance of intravascular volume [41•, 44]. Compared to FFP and fresh whole blood (FWB), LP has logistical benefits including reduced reliance on cold-chain storage, improved transportability, increased shelf life ( 2 years), and improved availability in austere pre-hospital settings [48]. In contrast to FWB, it can be preserved via multiple mechanisms including freezing, spray drying, or lyophilization [27]. In fact, freeze-dried plasma was used in World War II, but was discontinued due to disease transmission including hepatitis attributed to screening technique limitations [49].

Although FWB is preferred because it contains all blood components, it is not always feasible in the forward operational environment and is rarely used in the civilian setting [48]. To meet the needs of austere pre-hospital environments, there is growing use of the two most common forms of LP: German LyoPlas and French FlyP. Currently, LP is utilized for damage control resuscitation as the primary resuscitation fluid by the Israeli Defense Forces, French special forces, and in Germany, where dried plasma is also used in the civilian setting $[41 \cdot, 48$, $50,51]$. In Germany alone, there have been over 230,000 transfusions of LyoPlas since 2007 with a similar safety profile to FFP [50].

LP research is transitioning from proof of efficacy to optimization of the reconstitution process. A number of key concepts have recently been elucidated in traumatic swine models. LP reconstituted with water and ascorbic acid has been shown to reduce dysfunctional inflammation and oxidative DNA damage while reducing blood loss compared to FFP in a combat relevant multi-injury model in swine $[52,53]$. Reconstitution with sterile water and LR buffered with ascorbic acid resulted in decreased blood loss and an anti-inflammatory benefit compared to NS and Hextend. Furthermore, hemorrhage control is maintained when the volume of reconstituted fluid is reduced by $50 \%[54 \bullet \cdot]$. These low-volume, hypertonic, and hyperosmotic plasma formulations are ideally suited for POI use in forward surgical settings, allowing early treatment of ACT. 
Early plasma resuscitation has been shown to be safe and beneficial in multiple trials including several recent, large, multi-center civilian studies. Balanced resuscitation of plasma-packed red blood cells (PRBCs) can improve mortality, decrease total blood product requirements, and reduce complications [44, 47, 55••, 56••, 57, 58]. Current damage control resuscitation clinical practice guideline created by the United States (US) military, and many civilian massive transfusion protocols, dictate the use of plasma, platelets, and PRBCs in a 1:1:1 ratio in an effort to reproduce the effects of FWB [41 •]. Likewise, The American College of Surgeons issued guidelines in 2015 for trauma resuscitation recommending "Universal donor products should be immediately available on patient arrival to support a ratio-based transfusion [59]."

Fresh whole blood (FWB) is an amalgamation of procoagulant factors, oxygen-carrying red cells, and oncotic proteins that help mitigate coagulopathy and provide hemorrhage control [60, 61•]. FWB is currently utilized by the US Military in austere settings to augment available product as necessary. There are many logistical considerations when using FWB, especially the need for rapid screening protocols, due to risks to patients via transfusions that are not able to be screened in real time. Furthermore, the ready availability of FWB in the austere pre-hospital setting is limited by product availability and a short shelf life.

Damage control resuscitation is a significant part of patient care from POI to postoperative management. Appropriate controlled resuscitation with 1:1:1 product with early plasma administration provides the best opportunity for coagulopathy correction and hemorrhage control. LP is a safe and effective method for safely transitioning balanced resuscitation into the pre-hospital setting. Even with these resuscitation strategies, definitive surgical intervention with damage control surgery is often required in severely injured patients.

\section{Damage Control Surgery (Fig. 2)}

Damage control principles were initially described in the setting of urgent laparotomy [4]. Whereas this initial concept has been expanded to include the full spectrum of trauma care, the type and timing of surgical interventions remain crucial. The primary focus of surgical interventions has become a form of resuscitation with interventions in the acute phase selected by whether they will improve hemodynamic stability and avoid coagulopathy, hypothermia, and acidosis. This is in distinction from prior approaches which placed an emphasis on definitive repair.

The presence or threat of instability, major hemorrhage, vascular injury, acidosis, hypothermia, and/or coagulopathy is indications for damage control surgery [62]. When this pathway is entered, the operative goals are to decrease operative time to less than 1 hour, limit contamination, and control hemorrhage. Among patients that meet criteria for damage control laparotomy, there remains some controversy among civilian trauma centers as to whether the fascia should be left open in all cases with a planned "second look" as standard or selectively close the abdomen [63]. However, in the forward military setting, the abdomen is almost universally left open with a temporary closure device, partially to ensure full knowledge of injuries and intraabdominal interventions at higher echelons of care. At the conclusion of the procedure, communication of performed interventions is often written directly on the patient with indelible ink as a fail-safe for communication to higher echelons after evacuation.

Non-compressible torso hemorrhage (NCTH) is a challenge in decreasing battlefield mortality due to limited means of directly controlling hemorrhage once at the MTF as well as at the pre-hospital phase. Resuscitative endovascular balloon occlusion of the aorta (REBOA) is being implemented in the combat environment to mitigate against NCTH. Endovascular
Fig. 2 A forward surgical team operating theater

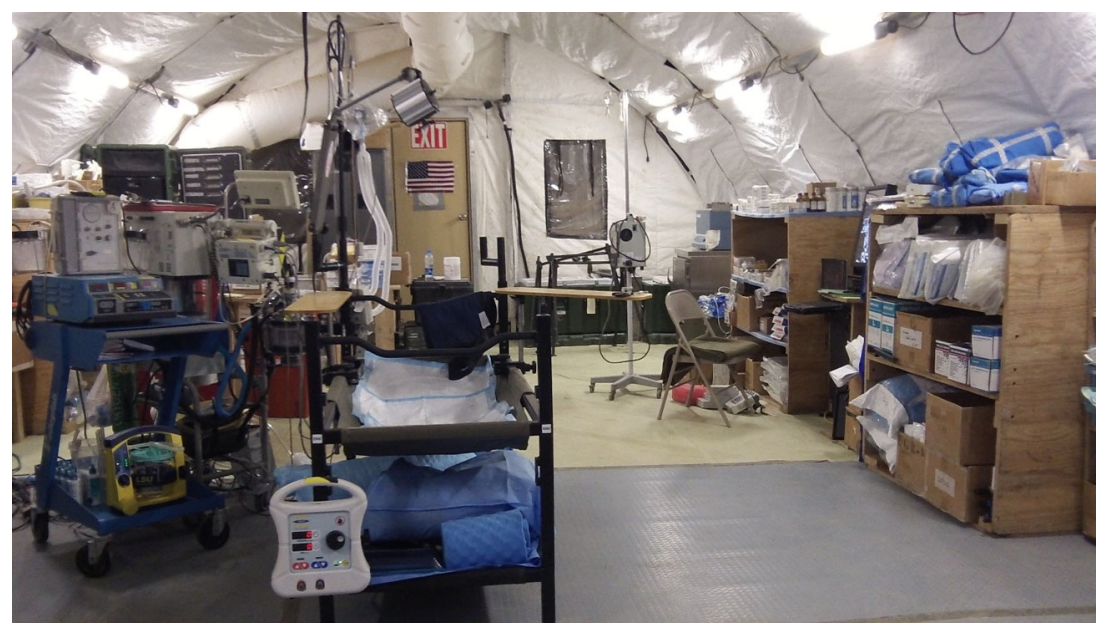


access is gained through the femoral artery and an occlusive balloon is inflated either above the celiac axis (for suspected intraabdominal hemorrhage) or above the aortic bifurcation (for suspected pelvic hemorrhage). This technology was first developed during the Korean War by Colonel Carl Hughes [64]. It has only recently gained increased application in the current era of improvements in endovascular technology. REBOA is not a definitive procedure in and of itself, but rather a bridge-buying time to obtain direct vascular control. In patients with recent or impending vascular collapse, REBOA is an appealing alternative to resuscitative thoracotomy. However, further study is required to establish whether REBOA or resuscitative thoracotomy is superior. Currently, the use of REBOA in theaters of operation is guided by a Joint Trauma System Clinical Practice Guideline [65, 66].

\section{Conclusion}

After over a decade of involvement in the conflicts in Afghanistan and Iraq, the military medical community has made many advances-some learned and some rediscovered from past wars. One of the major developments has been the concept of damage control, which now is beginning to encompass all levels of care from the POI to definitive care. The concept of preventing or rapidly addressing the components of the "lethal triad" predicates all steps the combat casualty takes from preventive interventions, self-aid at the scene, initial responders, evacuation, surgical interventions, and transport.

\section{Compliance with Ethical Standards}

Conflict of Interest Drs. Neilsen and Watson declare no conflicts of interest. Dr. Schreiber is a consultant for Arsenal Medical.

Human and Animal Rights and Informed Consent This article does not contain any studies with human or animal subjects performed by any of the authors.

\section{References}

Papers of particular interest, published recently, have been highlighted as:

- Of importance

•- Of major importance

1. Kotwal RS, Howard JT, Orman JA, Tarpey BW, Bailey JA, Champion HR, et al. The effect of a golden hour policy on the morbidity and mortality of combat casualties. JAMA Surg [Internet]. 2015;(Ahead of print). Available from: http://archsurg. jamanetwork.com/article.aspx?doi=10.1001/jamasurg.2015.3104. A retrospective study evaluating effects of decreased transport times in the Afghanistan conflict.
2. Eastridge BJ, Mabry RL, Seguin P, Cantrell J, Tops T, Uribe P, et al. Death on the battlefield (2001-2011). J Trauma Acute Care Surg. 2012;73(6):S431-7.

3.• Jenkins DH, Rappold JF, Badloe JF, Berseus O, Blackbourne L, Brohi $\mathrm{KH}$, et al. THOR position paper on remote damage control resuscitation: definitions, current practice, and knowledge gaps. Shock. 2014;41 Suppl 1:3-12. Position paper from a multinational network detailing the state of practice regarding Remote Damage Control Resuscitation (RDCR).

4. Stone HH, Strom PR, Mullins RJ. Management of the major coagulopathy with onset during laparotomy. Ann Surg. 1983;197(5): 532-5.

5. Rotondo MF, Schwab CW, McGonigal MD, Phillips GR, Fruchterman TM, Kauder DR, et al. "Damage control": an approach for improved survival in exsanguinating penetrating abdominal injury. J Trauma. 1993;35(3):375-83.

6. Tourtier J-P, Palmier B, Tazarourte K, Raux M, Meaudre E, Ausset S, et al. The concept of damage control: extending the paradigm in the prehospital setting. Ann Fr Anesth Reanim. 2013;32(7-8):520-6.

7. Director for the Joint Force Development. Department of Defense Dictionary of Military and Associated Terms, Joint Publication 102. Department of Defense. 2010. http://www.dtic.mil/doctrine/ new_pubs/jp1_02.pdf. Accessed 29 Mar 2016.

8. Kohn LT, Corrigan JM, Donaldson MS, Committee of Quality of Health Care in America-Institute of Medicine. To err is human. Washington D.C: The National Academies Press; 2000.

9. United States Army. Army Doctrine Publication No. 5-0 (ADP 5-0, FM 5-0), The Operations Process. Washington, DC: Department of the Army; 2012.

10. Gerhardt RT, Berry JA, Blackbourne LH. Analysis of life-saving interventions performed by out-of-hospital combat medical personnel. J Trauma. 2011;71(1 Suppl):S109-13.

11. Hooper TJ, Nadler R, Badloe J, Butler FK, Glassberg E. Implementation and execution of military forward resuscitation programs. Shock. 2014;41 Suppl 1:90-7.

12. Tourtier J, Palmier B, Tazarourte K, Raux M, Meaudre E, Ausset S, et al. The concept of damage control: extending the paradigm in the Le concept de damage control: extension pre. Ann Fr Anesth Reanim. 2013;32(7-8):520-6.

13. Hooper TJ, De Pasquale M, Strandenes G, Sunde G, Ward KR. Challenges and possibilities in forward resuscitation. Shock. 2014;41 Suppl 1:13-20.

14. Gerhardt RT. Prehospital and emergency care research at the US Army Institute of Surgical Research: enabling the next great leap in combat casualty survival. US Army Medical Department Journal. 2011;82-6. This paper sets the stage for prehospital resuscitation as the next major focus to improve survival from combat injury.

15. National Association of Emergency Medical Technicians. PHTLS: prehospital trauma life support, military edition. 8th ed. Saint Louis: Jones \& Bartlett Learning; 2014.

16. National Association of Emergency Medical Technicians. Tactical combat casualty care guidelines for medical personnel. Saint Louis: Jones \& Bartlett Learning; 2015.

17. Croushorn J, Thomas G, McCord SR. Abdominal aortic tourniquet controls junctional hemorrhage from a gunshot wound of the axilla. J Spec Oper Med. 2013;13(3):1-4.

18. Klotz JK, Leo M, Anderson BL, Nkodo AA, Garcia G, Wichern $\mathrm{AM}$, et al. First case report of SAM? Junctional tourniquet use in Afghanistan to control inguinal hemorrhage on the battlefield. J Spec Oper Med. 2014;14(2):1-5.

19. Anonymous. Abdominal aortic tourniquet use in Afghanistan. J Spec Oper Med. 2013;13(2):1-2. This article describes the first recorded use of an abdominal aortic tourniquet in a combat environment.

20. Littlejohn L, Bennett BL, Drew B. Application of current hemorrhage control techniques for backcountry care: part two, hemostatic 
dressings and other adjuncts. Wilderness Environ Med. 2015;26(2): 246-54.

21. Duggan M, Rago A, Sharma U, Zugates G, Freyman T, Busold R, et al. Self-expanding polyurethane polymer improves survival in a model of noncompressible massive abdominal hemorrhage. $\mathrm{J}$ Trauma Acute Care Surg. 2013;74(6):1462-7.

22. Rago A, Duggan MJ, Marini J, Beagle J, Velmahos G, De Moya MA, et al. Self-expanding foam improves survival following a lethal, exsanguinating iliac artery injury. J Trauma Acute Care Surg. 2014;77(1):73-7. A total of 39 animals were studied including the control and two dosage level groups with a significant decrease in hemorrhage rate after foam application for a lethal iliac injury.

23. Peev MP, Rago A, Hwabejire JO, Duggan MJ, Beagle J, Marini J, et al. Self-expanding foam for prehospital treatment of severe intraabdominal hemorrhage: dose finding study. J Trauma Acute Care Surg. 2014;76(3):619-24.

24. Bickell WH, Wall MJ, Pepe PE, Martin RR, Ginger VF, Allen MK, et al. Immediate versus delayed fluid resuscitation for hypotensive patients with penetrating torso injuries. N Engl J Med. 1994;331(17):1105-9.

25. Department of the Army. Army Techniques Publication No. 4-02.2 (ATP 4-02.2, FM 4-02.2). Washington, D.C: Department of the Army; 2014

26. Cubano M, Lenhart M. Emergency war surgery. 4th ed. Falls Church: U.S. Department of Defense, U.S. Army Office of the Surgeon General; 2013.

27. Burman S, Cotton BA. Trauma patients at risk for massive transfusion: the role of scoring systems and the impact of early identification on patient outcomes. Expert Rev Hematol. 2012;5(2):211-8.

28. Sauaia A, Moore FA, Moore EE, Moser KS, Brennan R, Read RA, et al. Epidemiology of trauma deaths: a reassessment. J Trauma. 1995;38(2):185-93.

29. Hoyt DB. A clinical review of bleeding dilemmas in trauma. Semin Hematol. 2004;41(1 Suppl 1):40-3.

30. Cohen MJ. Towards hemostatic resuscitation: the changing understanding of acute traumatic biology, massive bleeding, and damagecontrol resuscitation. Surg Clin North Am. 2012;92(4):877-91.

31. Schreiber MA. Coagulopathy in the trauma patient. Curr Opin Crit Care. 2005;11(6):590-7.

32. Maegele M, Lefering R, Yucel N, Tjardes T, Rixen D, Paffrath T, et al. Early coagulopathy in multiple injury: an analysis from the German Trauma Registry on 8724 patients. Injury. 2007;38(3): 298-304.

33. Maegele M, Spinella PC, Schochl H. The acute coagulopathy of trauma: mechanisms and tools for risk stratification. Shock. 2012;38(5):450-8.

34. Maegele M, Schöchl H, Cohen MJ. An update on the coagulopathy of trauma. Shock. 2014;41(S1):21-5. A review of the current understanding of trauma related coagulopathy to include both endogenous and exogenous mechanisms.

35. Frith D, Davenport R, Brohi K. Acute traumatic coagulopathy. Curr Opin Anaesthesiol. 2012;25(2):229-34.

36. Brohi K, Cohen MJ, Davenport RA. Acute coagulopathy of trauma: mechanism, identification and effect. Curr Opin Crit Care. 2007;13(6):680-5.

37. Pidcoke HF, Aden JK, Mora AG, Borgman MA, Spinella PC, Dubick MA, et al. Ten-year analysis of transfusion in Operation Iraqi Freedom and Operation Enduring Freedom: increased plasma and platelet use correlates with improved survival. J Trauma Acute Care Surg. 2012;73(6 Suppl 5):S445-52.

38. Hess JR, Lawson JH. The coagulopathy of trauma versus disseminated intravascular coagulation. J Trauma. 2006;60(6 Suppl):S129.
39. MacLeod JBA, Lynn M, McKenney MG, Cohn SM, Murtha M. Early coagulopathy predicts mortality in trauma. J Trauma. 2003;55(1):39-44.

40. Whittaker B, Christiaans SC, Altice JL, Chen MK, Bartolucci AA, Morgan CJ, et al. Early coagulopathy is an independent predictor of mortality in children after severe trauma. Shock. 2013;39(5):421-6.

41. Glassberg E, Nadler R, Gendler S, Abramovich A, Spinella PC, Gerhardt RT, et al. Freeze-dried plasma at the point of injury: from concept to doctrine. Shock. 2013;40(6):444-50. Details the introduction of freeze dried plasma by the Israeli Defense Forces by initial responders.

42. Alam HB, Bice LM, Butt MU, Cho SD, Dubick MA, Duggan M, et al. Testing of blood products in a polytrauma model: results of a multi-institutional randomized preclinical trial. J Trauma. 2009;67(4):856-64.

43. Sondeen JL, Coppes VG, Holcomb JB. Blood pressure at which rebleeding occurs after resuscitation in swine with aortic injury. J Trauma. 2003;54(5 Suppl):S110-7.

44. Lee L, Moore EE, Hansen KC, Silliman CC, Chandler JG, Banerjee A. It's not your grandfather's field plasma. Surgery. 2013;153(6): $857-60$.

45. Holcomb JB, Jenkins D, Rhee P, Johannigman J, Mahoney P, Mehta S, et al. Damage control resuscitation: directly addressing the early coagulopathy of trauma. J Trauma. 2007;62(2):307-10.

46.• Moore HB, Moore EE, Gonzalez E, Wiener G, Chapman MP, Dzieciatkowska M, et al. Plasma is the physiologic buffer of tissue plasminogen activator-mediated fibrinolysis: rationale for plasmafirst resuscitation after life-threatening hemorrhage. J Am Coll Surg. $2015 ; 220(5): 872-9$. This paper compares thromboelastography-based coagulation in vitro of blood mixed with either crystalloid or plasma with demonstration favoring plasma.

47. Novak DJ, Bai Y, Cooke RK, Marques MB, Fontaine MJ, Gottschall JL, et al. Making thawed universal donor plasma available rapidly for massively bleeding trauma patients: experience from the pragmatic, randomized optimal platelets and plasma ratios (PROPPR) trial. Transfusion. 2015;55(6):1331-9.

48. Pennardt A. The time to field freeze dried plasma is now. J Spec Oper Med. 2010;10(3):49.

49. Schmidt PJ. The plasma wars: a history. Transfusion. 2012;52 Suppl 1:2S-4.

50. Bux J, Dickhörner D, Scheel E. Quality of freeze-dried (lyophilized) quarantined single-donor plasma. Transfusion. 2013;53(12):3203-9.

51. Martinaud C, Ausset S, Deshayes AV, Cauet A, Demazeau N, Sailliol A. Use of freeze-dried plasma in French intensive care unit in Afghanistan. J Trauma. 2011;71(6):1761-4. discussion 1764-5.

52. Van PY, Hamilton GJ, Kremenevskiy IV, Sambasivan C, Spoerke NJ, Differding JA, et al. Lyophilized plasma reconstituted with ascorbic acid suppresses inflammation and oxidative DNA damage. J Trauma. 2011;71(1):20-4. discussion 24-5.

53. Hamilton GJ, Van PY, Differding JA, Kremenevskiy IV, Spoerke NJ, Sambasivan C, et al. Lyophilized plasma with ascorbic acid decreases inflammation in hemorrhagic shock. J Trauma. 2011;71(2):292-7. discussion 297-8.

54.• Lee TH, Watson K, Fabricant L, Barton J, Differding J, Kremenevskiy I, et al. Hyperosmolar reconstituted lyophilized plasma is an effective low-volume hemostatic resuscitation fluid for trauma. J Trauma Acute Care Surg. 2013;75(3):369-75. This animal study is one of several from the same lab evaluating the ideal reconstitution of freeze dried plasma for resuscitative use.

55.• Holcomb JB, del Junco DJ, Fox EE, Wade CE, Cohen MJ, Schreiber MA, et al. The prospective, observational, multicenter, major trauma transfusion (PROMMTT) study: comparative effectiveness of a time-varying treatment with competing risks. JAMA Surg. 2013;148(2):127-36. A large prospective multicenter 
study demonstrating a mortality benefit to higher plasma:red cell and platelet:red cell ratios when delivered early after trauma.

56.• Holcomb JB, Tilley BC, Baraniuk S, Fox EE, Wade CE, Podbielski $\mathrm{JM}$, et al. Transfusion of plasma, platelets, and red blood cells in a 1: $1: 1$ vs a $1: 1: 2$ ratio and mortality in patients with severe trauma: the PROPPR randomized clinical trial. JAMA. 2015;313(5):471-82. A large prosective multicenter trial demonstrating similar mortality (the primary outcome measure), but more patients achieved hemostasis in the 1:1:1 group.

57. Peiniger $\mathrm{S}$, Nienaber $\mathrm{U}$, Lefering $\mathrm{R}$, Braun $\mathrm{M}$, Wafaisade $\mathrm{A}$, Wutzler $\mathrm{S}$, et al. Balanced massive transfusion ratios in multiple injury patients with traumatic brain injury. Crit Care. 2011;15(1):R68.

58. del Junco DJ, Holcomb JB, Fox EE, Brasel KJ, Phelan HA, Bulger $\mathrm{EM}$, et al. Resuscitate early with plasma and platelets or balance blood products gradually: findings from the PROMMTT study. J Trauma Acute Care Surg. 2013;75(1 Suppl 1):S24-30.

59. American College of Surgeons. American College of Surgeons Trauma Quality Improvement Project (ACS TQIP) massive transfusion in trauma guidelines. Transfusion in the Intensive Care Unit. 2015. pp. 101-19.

60. Jenkins D, Stubbs J, Williams S, Berns K, Zielinski M, Strandenes $\mathrm{G}$, et al. Implementation and execution of civilian remote damage control resuscitation programs. Shock. 2014;41 Suppl 1:84-9.

61. Murdock AD, Berséus O, Hervig T, Strandenes G, Lunde TH. Whole blood: the future of traumatic hemorrhagic shock resuscitation. Shock. 2014;41 Suppl 1:62-9. The history and recent experiences with whole blood are reviewed in order to establish support for a prospective randomized trial comparing whole blood with component therapy.

62. Asensio JA, McDuffie L, Petrone P, Roldań G, Forno W, Gambaro E, et al. Reliable variables in the exsanguinated patient which indicate damage control and predict outcome. Am J Surg. 2001;182(6): $743-51$.

63. Higa G, Friese R, O’Keeffe T, Wynne J, Bowlby P, Ziemba M, et al. Damage control laparotomy: a vital tool once overused. J Trauma. 2010;69(1):53-9.

64. Hughes CW. Use of an intra-aortic balloon catheter tamponade for controlling intra-abdominal hemorrhage in man. Surgery. 1954;36(1):65-8.

65. Joint Theater Trauma System. Joint Theater Trauma System Clinical Practice Guideline Resuscitative Endovascular Balloon Occlusion of the Aorta (REBOA) for Hemorrhagic Shock. San Antonio: Joint Theater Trauma System; 2014. pp. 1-18.

66. Stannard A, Eliason JL, Rasmussen TE. Resuscitative endovascular balloon occlusion of the aorta (REBOA) as an adjunct for hemorrhagic shock. J Trauma. 2011;71(6):1869-72.

The views expressed in this article are those of the author and do not reflect the official policy or position of the Department of the Army, the Department of Defense, or the US Government. 